\title{
A Rare Tumor of the Scalp
}

\section{El Anzi O*, Sqalli A, Maouni S, Hassam B and Ismaili N}

Department of Dermatology-Venereology, Ibn Sina University Hospital, Mohammed V

University, Morocco

${ }^{*}$ Corresponding author: El Anzi Ouiam, Department of Dermatology-Venereology, Ibn Sina University Hospital, Mohammed V University, Rabat, Morocco, Tel: 002126

\begin{tabular}{|c|}
\hline Case Report \\
Volume 4 Issue 1 \\
Received Date: January 24,2019 \\
Published Date: March 01,2019 \\
DoI: $10.23880 /$ cdoaj-16000174 \\
\hline
\end{tabular}
2460 4105; Email: elanzi.ouiam@gmail.com

\section{Abstract}

The Trichilemmal carcinoma (TC) is a rare skin adnexal malignant tumor that develops from the outer root sheath of hair follicles or most often from a trichilemmal cyst, after multiple trauma and / or iterative inflammations. We report the case of a 64-year-old patient who consulted for a scalp tumor, evolving progressively for 2 years.

Keywords: Trichilemmal carcinoma; Malignant; Scalp

\section{Introduction}

Trichilemmal carcinoma (TC) is an infrequent malignant tumor that develops from the external root sheath of the hair follicle. It is located most often at the scalp, and neck,or upper extremities, and generally has an indolent clinical course.

\section{Clinical Case}

We report the case of a 64-year-old patient who consulted for a scalp tumor, evolving progressively for 2 years (Figures 1 and 2).

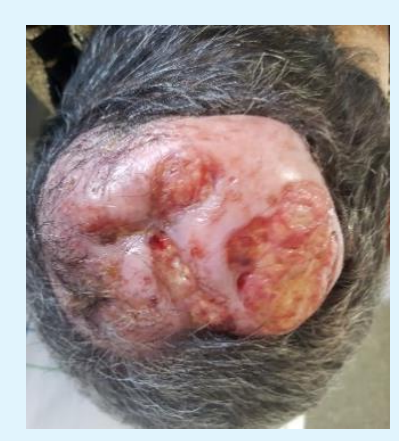

Figure 1: Exophytic tumor mass, ulcerative budding, $12 \mathrm{~cm}$ in major axis, on the vertex.

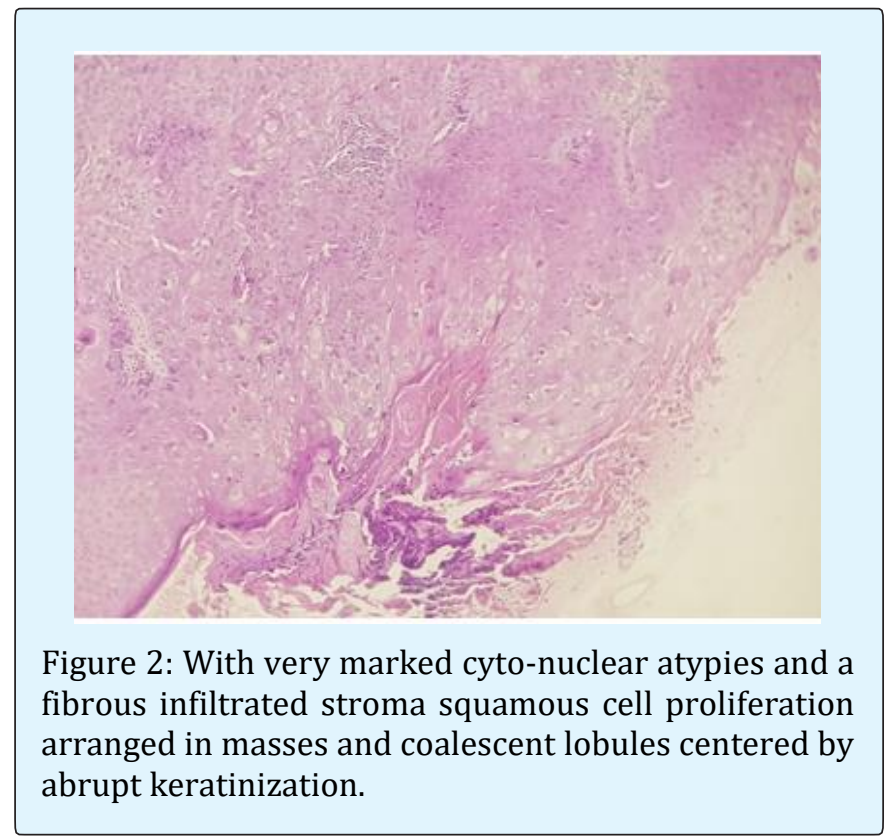

Clinical examination showed a painful, firm and rounded formation of $15 \mathrm{~cm}$ diameter, on the vertex with absence of locoregional adenopathies. The histological examination showed a squamous cell proliferation arranged in masses and coalescent lobules centered by 


\section{Clinical Dermatology Open Access Journal}

abrupt keratinization according to a trichilemmal mode, with very marked cyto-nuclear atypies and a fibrous infiltrated stroma, evoking a trichilemmal carcinoma. A complete assessment did not find a metastasis. The patient underwent extensive surgical excision, without recurrence with a 1-year follow-up.

\section{Discussion}

The Trichilemmal carcinoma (TC) is a rare skin adnexal malignant tumor that develops from the outer root sheath of hair follicles or most often from a trichilemmal cyst, after multiple trauma and / or iterative inflammations $[1,2]$.

Clinical manifestations are multiple, mimicking basal or squamous cell carcinomas, keratoacanthomas and nodular melanomas [2]. The diagnosis of trichilemmal carcinoma is established by means of histopathological examination in and the presence of abnormal mitoses, high mitotic rate, marked cellular pleomorphism, cytologic and architectural atypia, infiltrating margin, necrosis, and aneuploidy [3].

Surgical excision is considered the first choice for curative treatment TC with a $1-\mathrm{cm}$ safety margin to prevent recurrence. Although, in some cases ethanol injection, lymph node dissection, radiotherapy, and chemotherapy can be considered $[2,4]$.

Trichilemmal carcinoma may exhibit aggressive invasion, even intracranially, causing considerable morbidity and even mortality $[3,4]$.

\section{Conclusion}

Examination of Patients with trichilemmal cyst should take into consideration the possibility of malignant transformation. Close follow-up is essential for early identification of recurrence.

\section{Conflict Interest}

The authors don't declare any conflicts of interest.

\section{References}

1. Xu DB, Wang T, Liao Z (2018) Surgical Treatment of Trichilemmal Carcinoma. World J Oncol 9(5-6): 141144.

2. Kim UG, Kook DB, Kim TH, Kim CH (2017) Trichilemmal Carcinoma from Proliferating Trichilemmal Cyst on the Posterior Neck. Arch Craniofac Surg 18(1): 50-53.

3. D'Avila DG, Kanno DT, de Castilho da Silva D, Pastro VR, Novelli PCS, et al. (2018) A proliferating trichilemmal cyst in the perianal region: A case report. Int J Surg Case Rep 53: 175-178.

4. Maya-Rico AM, Jaramillo-Pulgarín C, Londoño-García Á, Peña-Zúñiga B (2018) Locally aggressive trichilemmal carcinoma. An Bras Dermatol 93(4): 579-581. 